\title{
EN ESAS MELODÍAS NOS MECEMOS
}

\section{Texto leído como presentación del libro LA VERDADERA HISTORIA DE LA SALSA del escritor Medardo Arias. Evento llevado a cabo en el Centro Cultural de Cali el jueves 24 de enero de 2013.}

\section{Darío Henao Restrepo Decano Facultad de Humanidades}

Me complace y le acepté a Medardo su gentil invitación para presentar este libro, debo confesarlo, porque me cogió en caliente, esto es, por ser la música parte esencial de todo el universo cultural, histórico, artístico y literario del cual me vengo ocupando en los últimos años - el doctorado en Historias, Sociedades y Culturas Afro-Latinoamericanas de la Facultad de Humanidades, el Centro Virtual Isaacs como proyecto de recuperación de la Memoria cultural del Pacífico colombiano y en el programa de televisión Conversan Dos y el sinnúmero de entrevistas con nuestros músicos - lo que me ha llevado a muchas lecturas y experiencias, todas muy próximas de los temas que nos trae Medardo en La verdadera historia de la salsa. Como en su libro anterior, Palabra Afroamericana, dedicado a las obras literarias de las Américas en la cual se da cuenta de todo el legado y los aportes de los negros en nuestras sociedades, en este Medardo vuelve al género del ensayo para ocuparse de todas las vertientes musicales afrocaribeñas, en especial la cubana y la puertorriqueña, que configuraron lo que se conoce como la salsa, esa denominación que tanto molestaba al gran Tito Puente. Para el rey del timbal la salsa no era un género musical y señalaba "lo que llaman salsa lo he tocado desde hace muchísimos años: se llama mambo, guaracha, chachachá, guaguancó. Todo es música cubana. La salsa se come, no se oye, se baila." Lo que Medardo hace es poner en su punto este movimiento musical, que diferencias aparte y variedad de interpretaciones, ya tiene su lugar en el mundo como el jazz, el rock, el tango o el samba. Vale un aquí una cita que resume la perspectiva del libro: 
(...) aunque Cuba dio las claves rítmicas, fueron los músicos puertorriqueños afincados en Nueva York, los que permitieron, junto a la bomba y la plena, y la apropiación particular "neoyorriqueñamente" caracterizada- del sonido cubano, la fragua de la salsa. (p.40)

Y más, Medardo precisa un mítico club de baile en Nueva York como el epicentro del surgimiento de esta fusión de músicas afrocaribeñas:

Músicos tales como Tito Puente, Jhonny Pacheco, Eddie y Charlie Palmieri, Bobby Valentín, Pete Rodríguez, Ricardo Richie Ray, Willie Colón, Ray Barreto, Joe Bataan,Rafael Ithier, Kike y Pappo Lucca, Roberto Roena, Reinaldo Jorge, Milton Cardona, Manny Oquendo, recogieron el legado de los días febriles del "Palladium Ballroom", el club de Manhattan que cerró sus puertas a mediados de los 60, para "cocinar", en la capital del mundo, lo que hoy se conoce como "salsa". (p. 42)

Y puntualiza:

Este ritmo que es hijo de tantas razas. Pertenece por igual a Cuba, a Nueva York, a Puerto Rico, a Barlovento, a Buenaventura, a Cali, o a Quibdó, a orillas del río Atrato. (P.45)

El núcleo social de goce y disfrute de las músicas de la salsa siempre fue el barrio, sus salones de baile, universo alimentado por la radio y las casas disqueras. No es el momento, pero al menos vale señalar que para completar su estudio es preciso contemplar la historia del baile, de sus bailadores, el papel de la radio y la producción discográfica. Las investigaciones del profesor Alejandro Ulloa han aportado mucho sobre el papel del barrio, empezando por el Harlem Hispano y el South Bronx en Nueva York, albergue de los inmigrantes latinos. Esto, por supuesto, acompañado de los estudios de los musicólogos que ayudan a explicarla en sus aspectos rítmicos, melódicos, armónicos e instrumentales. Y por supuesto de la dimensión sociológica y antropológica para entender su papel en nuestras comunidades.

En mi reciente visita a Puerto Rico tuve la oportunidad de visitar los barrios de Rafael Cortijo, Ismael Rivera, Daniel Santos, Cheo Feliciano y Tite Curet Alonso: Santurce, Llorens Torres, Trastalleres, Villa Palmera, Loíza y La Perla, lugares de mayoría afroborinqueña, también visitados por Medardo cuando realizó su investigación para 
escribir estas crónicas que le valieron el premio nacional de periodismo Simón Bolívar en 1982. Estos recorridos los hice ciceroneado por mi amigo el musicólogo boricua Ángel Quintero, con quien fui a visitar al cubano Cristóbal Díaz Ayala, a sus 83 años uno de los más grandes investigadores de la música del Caribe. También compartí en el Festival de La Palabra con los más destacados escritores de Puerto Rico, muchas de cuyas novelas están atravesadas por la música, me refiero a Luis Rafael Sánchez con La guaracha del macho Camacho y La importancia de llamarse Daniel Santos; a Edgardo Rodriguez Juliá con El entierro de Cotijo y a Mayra Santos con Sirena selene vestida de penas y Medicina Tropical; autores que tienen entre nosotros pares como Andrés Caicedo con Viva la música, Umberto Valverde con Bomba Camará y Reina rumba, Óscar Collazos con Son de máquina, Fernando Cruz Kronfly con La caravana de Gardel, Fabio Martinez con El tumbao de Bethoven y Medardo Arias con Jazz para difuntos y Que es un soplo la vida. Todo esto estuvo animado por realidades histórico-culturales que tenemos que ahondar y comprender: las profundas relaciones de Cali y el Pacífico con el Caribe. Con este propósito invitamos a todos estos artistas e intelectuales a la Feria del Libro Pacífico, que tendrá este año a Puerto Rico como país invitado, y cuyo tema será la Música y la Literatura y se le rendirá homenaje a Richie Ray y Bobby Cruz y a la música de la Isla del encanto que tanto queremos en Cali, en Buenaventura, en Quibdó o en Tumaco, para no hablar de otras tantas ciudades de Colombia. Será una excelente oportunidad para que nuestros músicos, investigadores y escritores entablen un fructífero diálogo sobre estos temas tan importantes para la cultura de esta ciudad y el Pacífico colombiano.

Hay en todo esto que he mencionado un universo de expresiones artísticas de suma importancia para la cultura de Cali por lo que representa esta ciudad como espacio de confluencias del Pacífico colombiano y con tan hondas conexiones con el Caribe. Asunto que necesita ser profundizado si queremos darle norte y proyección a nuestra cultura en el mundo. Enhorabuena llega este libro de Medardo sobre la salsa, pues sus indagaciones se complementan con las que hiciera en el dedicado a la literatura. El tratamiento de estos asuntos en la pluma de su autor alcanzan la dimensión reflexiva que ameritan como objetos de conocimiento fundamentales para nuestra cultura. Vale en esta dimensión destacar que entre ambos libros existen vasos comunicantes que llaman la atención sobre una 
característica: la Literatura y la Música, su entrecruzamiento, hacen parte de la configuración de las identidades urbanas de muchas ciudades de este continente, en particular la de Cali, una ciudad mulata y mestiza caracterizada por beber y apreciar las diversas tradiciones musicales que en ella se han aclimatado. Fenómeno que en el campo de la música ha sido fértil para la conformación de sus propias sonoridades, acompasadas con sus movimientos urbanos y sus diálogos con otros ámbitos. Muy bien ubica Medardo, como fruto de estos procesos, la aparición del maestro Jairo Varela y el Grupo Niche. Esta música la define

“como una afortunada fusión entre el bambuco viejo, el berejú, el patacoré, la jota chocoana y los alabaos, con los ritmos de las Antillas.” (p.262)

Mucho ritmo, mucho swing y mucha poesía animan los análisis y reflexiones de esta verdadera historia de la salsa escrita por Medardo. Como lo dije del libro Cuerpo y Cultura. Las músicas "mulatas" y la subversión del baile, de Ángel Quintero, este libro también nos brinda la posibilidad de disfrutar su lectura cantando y bailando. Ayudado de mi Ipad y el acceso a la infinita discoteca de You Tube pude recrear toda la memoria de las músicas aludidas en el libro, tararear con un sabrosón baile de silla muchas canciones, y más aún, reflexionar sobre el significado para nuestra cultura de temas, menciono al azar, como El son de la Ma Teodora de Teodora Ginés, Lamento borincano de Rafael Hernández, Sin negro no hay guaguancó de Tite Curet Alonso, Déjala que suba de Ismael Rivera, Menéame la cuna Ramón de Ñico Saquito, Son de la loma de Miguel Matamoros, Échale salsita de Arsenio Rodríguez o Zafra de Richie Ray, una lista interminable. Destaco esto porque es lo que con trazos y pinceladas poéticas hace Medardo en este vasto recorrido por la genealogía de la salsa, remontándonos a los tambores traídos por los esclavos africanos y todo lo que en su resistencia y lucha por la libertad forjaron en el Nuevo Mundo. Qué viva changó, señores reza el estribillo de la canción de Celina bailada en todas nuestras fiestas. Referencia que alude a un contenido de fondo: la presencia de la religiosidad afrocaribeña y todo su santoral, muchas veces sincretizado con el santoral católico. Aspecto que Medardo señala en muchas de las canciones, e inclusive, en las prácticas y devociones de los músicos con los dioses africanos. 
La salsa como mezcla de tantas corrientes musicales no se podría explicar sin el tambor como instrumento central de la vertiente afroamericana. Esa lejana África que acá llegó con la infame trata de esclavos, en buena parte explica nuestra particular manera de ser, de sentir y de expresarnos, que hoy nos distingue y nos relaciona con la extraordinaria complejidad y multiplicidad del mundo en el cual vivimos. Esto lo recuerda la canción del Tite Curet Alonso, Primoroso cantar, interpretada por el Pete "El Conde" Rodríguez con la Orquesta de Johnny Pacheco:

"Primoroso cantar

que comenzó en un barracón

cuando mi gente llegó

del África lejana

trayendo un tambor",

A esa vasta genealogía de ancestros africanos están filiados los sones de esta ciudad, ellos son la oculta compañía que todos llevamos por dentro. Asomarnos a la ventana de la memoria vivida en sus calles y en sus barrios es imposible no asociarlo con el río de melodías que han acompañado su devenir colectivo y la condición alegre, abierta y sandunguera de sus gentes. Sin duda este es el asunto de fondo tratado en el libro de Medardo, La verdadera historia de la salsa. La historia de esas músicas que con el nombre de salsa forjaron una poderosa expresión de los latinos en Nueva York con inmediata repercusión en los países de origen y en el mundo. Cubanos y Puertorriqueños, los que más, pero también dominicanos, panameños, colombianos, venezolanos, mexicanos y peruanos, contribuyeron e hicieron suya esta expresión de identidad y afirmación en su condición de inmigrantes en las grandes metrópolis norteamericanas. Como apunta Alejandro Ulloa en La salsa en discusión, en este circuito migratorio se cocina la salsa, como producto de una población semi-nómada en tránsito permanente entre su tierra natal y el exilio. (p.78)

El libro nos brinda un vasto panorama de las sonoridades de nuestras músicas mulatas y la subversión del baile, como denomina el musicólogo Ángel Quintero a la inseparable relación que se vive entre el cuerpo y la música en nuestras sociedades. Esas músicas "mulatas" han provocado las delicias del cuerpo, los encuentros amorosos, la amistad, la solidaridad, la alegría y el humor, el dolor y la tristeza, en fin, esas simples épicas que llenan la vida de la gente. La salsa, entonces, según Medardo, tiene todos nuestros defectos 
y virtudes. Es como una muchacha limpia, apenas bañada, llevándonos al mundo de la fragancia, prometiéndonos agua de regaliz; en ese aroma nos mecemos. ¡Qué gran perfume! Muchos ritmos, melodías e ideas han bullido por dentro al leer esta historia que nos regala Medardo, con certeza eso acontecerá con todos ustedes. Este sentimiento me lleva a expresarles que de ahí devienen mis afinidades intelectuales con su obra desde que leí su poemario Luces de Navegación, sus novelas Jazz para difuntos y Que es un soplo la vida, hasta Palabra Afroamericana, ese valioso libro de ensayos ya mencionado, al que tuve la honra de presentar el año pasado. Para la cultura de la región Pacífico y de Cali como su epicentro, contar con la obra de Medardo Arias, este hijo de Buenaventura recalado en Cali, constituye un punto alto de reflexión, conocimiento y expresión estética, en momentos en los cuales esta ciudad y esta región necesita de nuevos rumbos y para lo cual el aporte de sus artistas e intelectuales debe ser un referente para sus gobernantes y ciudadanos.

Dos cosas quiero destacar por lo que a partir de ellas se puede adelantar. La primera, el club Bronx Casino de Nueva York, propiedad de un cubano de apellido Macera, según cuenta Eddy Palmieri, un lugar frecuentado por los marinos de la Flota Mercante de Colombia, muchos de ellos traían esa música a Buenavetura, en el caso del Pacífico, y a Barranquilla y Cartagena, en el caso del Caribe. Así como los marinos caribeños que venían en los barcos de la Graceline. Del bello puerto cantado por Petronio y Peregollo se irradiaba la "pasta" (los discos) como joyas a Cali, y lo destacó porque este es un capitulo que está por escribirse, el de la música en Buenaventura y sus relaciones con Cali. La segunda, es el amoroso homenaje que Medardo le rinde en el capítulo final a su compañera, la musicóloga Lise Waxer, quien dedicó su investigación a la influencia de los ritmos antillanos y vivió un par de años en Cali. De ese periplo quedaron muchas cosas y un libro, La ciudad de la memoria musical, apenas publicado en inglés, y que valdría la pena su traducción y publicación entre nosotros. Todo esto contribuiría a la importante bibliografía sobre la música popular en Cali, que ya cuenta con libros como La historia de la salsa en Cali, La Salsa en discusión y la multimedia de la salsa de Alejandro Ulloa, los innumerables textos de Gary Dominguez - El cuaderno Latino de la Salsa y sus audiciones de La taberna latina- y los de Orlando Montenegro en la revista Melómanos documentos, los libros de Pablo del Valle El son es universal y Arsenio Rodriguez, los libros de Umberto Valverde sobre la Sonora Matancera, Celia Cruz, las orquestas femeninas- Abran paso - , y su más 
reciente, Jairo Varela. Que todo el mundo te cante, cuyo original he leído por gentileza de Umberto, libro que todos los caleños podrán leer y coleccionar en 20 entregas todos los domingos a partir de este 29 de enero en el diario El País.

Una vez leída esta historia de la salsa, que hoy nos entrega Medardo, tan bien documentada, al mismo tiempo que disfrutada, pensada y poetizada, puedo asegurarles que el viaje por las páginas del libro es como asistir a una fiesta, guateque, rumba, aguaelulo, bailongo, entre tantos nombres habidos para nombrar este ritual danzario, en la cual todo el repertorio musical resulta entrañable, familiar e íntimo, quizás, porque como decía Alejo Carpentier, tanto en la literatura como en la música, a los latinoamericanos nos hermana ese "aire de familia" fruto de compartir las mismas vertientes que nos constituyen.

Al final dan ganas de rumbantela, de salir a buscar la melodía en este Cali pachanguero. 